\title{
SISTEM INFORMASI PENGADAAN BARANG BERBASIS WEB PADA PT. ARPAN BALI UTAMA
}

\author{
Ni Kadek Sutriasih¹ , I Made Dwi Putra Asana² , Ni Putu Suci Meinarni³ \\ Prodi Teknik Informatika, STMIK STIKOM Indonesia
}

\begin{abstract}
Abstrak
PT Arpan Bali Utama merupakan perusahaan manufaktur yang bergerak dalam bidang produksi minuman wine. Adapun beberapa permasalahan yang ada yaitu disaat proses pencatatan transaksi pembelian dan penerimaan barang, serta permasalahan lainnya yaitu, pihak manager tidak memiliki laporan perbandingan pemesanan dan penerimaan sehingga tidak diketahui bagaimana pelayanan dari pihak supplier. Solusi dari masalah tersebut adalah dengan membangun sistem pengadaan barang. Langkah - langkah yang dilakukan dalam tahap pengembangan sistem ini antara lain dengan metode: analisis perancangan, implementasi dan pengujian sistem dengan black box testing dan pengujian User Acceptance Test (UAT). Hasil dari penelitian bahwa sistem informasi pengadaan barang dapat membantu perusahaan dalam pencatatan dan pelaporan pengadaan barang. Terdapat fitur data barang, data supplier, data purchase order, data penerimaan, data pembayaran serta data penjualan yang berfungsi dalam pencatatan pembelian dan penjualan barang. Selain itu juga terdapat fitur penjurnalan yang berfungsi untuk pencatatan biaya-biaya pada perusahaan. Manager perusahaan juga dapat mencetak laporan pembelian, penjualan, perbandingan, penerimaan, laporan jurnal, buku besar, laba rugi serta laporan neraca saldo. Hasil pengujian menggunakan metode black box testing dan pengujian User Acceptance Test (UAT). Metode black box testing menunjukkan bahwa semua fitur yang terdapat dalam sistem berjalan dengan baik sesuai fungsinya. Sedangkan hasil pengujian User Acceptance Test terhadapat sistem pendukung keputusan ini memperoleh persentase $86.5 \%$.
\end{abstract}

Kata Kunci:

Sistem Informasi, Pengadaan Barang, Jurnal, Akuntansi.

\begin{abstract}
PT Arpan Bali Utama is a manufacturing company in the production of wine. There are few problematic that was happening, such as noted transaction process of the items that have been bought, noted of process of receiving the items and also the manager did not have the comparative documentation of ordering and receiving which made us confused about what was happening. The solution to this problem is to build a procurement system. The steps taken in the development stage of this system include the following methods: design analysis, implementation and system testing with black box testing and User Acceptance Test (UAT). The results of the research show that the procurement information system can assist companies in recording and reporting procurement of goods. There are features of goods data, supplier data, purchase order data, receipt data, payment data and sales data that function in recording purchases and sales of goods. In addition, there is also a journaling feature that functions to record costs at the company. Company managers can also print reports on purchases, sales, comparisons, receipts, journal reports, general ledgers, profit and loss and trial balance reports. The test results use the black box testing method and the User Acceptance Test (UAT). The black box testing method shows that all the features contained in the system are running well according to their functions. While the results of the User Acceptance Test for this decision support system obtained a percentage of $86.5 \%$.
\end{abstract}

Keywords:

Information Systems, Procurement of Goods, Journal, Accounting.

\section{PENDAHULUAN}

Proses pengadaan barang pada suatu perusahaan merupakan hal terpenting yang harus dilakukan untuk memenuhi kebutuhan produksi pada perusahaan tersebut. Manajemen menyusun standar operasional prosedur sesuai dengan karakteristik perusahaan untuk mengendalikan jumlah persediaan. 
Hal tersebut bertujuan untuk menjamin alur pengadaan tetap berjalan dengan baik selama perusahaan tersebut masih produktif. Selain standar operasional yang baik dibutuhkan juga infrastruktur pendukung untuk menjalankan aturan tersebut. Infrastruktur pendukung yang dimaksud adalah teknologi informasi yang mampu membantu proses pencatatan dan pengolahan data bagi manajemen.

PT Arpan Bali Utama merupakan perusahaan manufaktur yang bergerak dalam bidang produksi minuman wine. Dalam pembuatan wine, perusahaan mebutuhkan waktu berbulan-bulan hingga satu tahun lamanya untuk memproduksi kurang lebih 1000 minuman per sekali produksi, dengan kisaran 500 jumlah item dan rata-rata 300 transaksi perharinya. Pada proses pencatatan transaksi tersebut dilakukan oleh purchasing yang melakukan pemesanan dengan membuat purchase order, warehouse melakukan penerimaan barang dan accounting melakukan pembayaran dengan berdasarkan nota yang diterima. Disana juga terlibat cost control, dan general manager sebagai yang menyetujui purchase order tersebut.

Adapun hal-hal yang menjadi permasalahan yaitu, disaat purchasing melakukan pemesanan barang, pihak purchasing membutuhkan waktu yang lama untuk menunggu tanda tangan persetujuan purchase order dari pihak cost control dan general manager karena tidak selalu ada diruangan atau kantor. Maka, purchase order akan menumpuk yang menyebabkan sering terjadi kehilangan purchase order sehingga proses pemesanan barang menjadi tertunda. Kemudian pada proses pencatatan penerimaan barang, pihak warehouse sering kali kebingungan mencari dokumen purchase order untuk dibandingankan dengan barang yang diterima, karena terlalu banyaknya dokumen purchase order. Permasalahan lainnya yaitu, pihak manager tidak memiliki laporan perbandingan pemesanan dan penerimaan sehingga tidak diketahui bagaimana pelayanan dari pihak supplier yang dimana, laporan tersebut dibutuhkan sebagai data dukung untuk pindah supplier. Selain itu pada saat manager membutuhkan laporan mengenai pemesanan, penerimaan dan pembayaran, harus menunggu lama data tersebut direkap satu persatu oleh pihak purchasing, warehouse dan accounting karena harus mencari arsip-arsip dokumen yang jumlahnya banyak. Kurangnya keamanan data, seperti kehilangan data juga terjadi saat pengarsipan dokumen terutama pada saat dokumen semakin banyak sehingga terjadi penumpukan data. Hal inilah yang menyebabkan kesulitan dalam pencarian data apabila diperlukan sewaktu-waktu.

Penelitian terdahulu yang berkaitan dengan topik sistem informasi pengadaan barang sudah pernah dilakukan sebelumnya oleh (Oktarina \& Widjaja, 2019), dengan judul "Rancang Bangun Sistem Informasi Pengadaan Barang Pada CV. Mitra Anugerah". Masalah dalam penelitian tersebut adalah Belum ada informasi data pemesanan barang, penerimaan barang, retur barang, pembayaran ke supplier, dan stok barang karena belum diketahui secara jelas barang yang dikelola. Selain itu permasalahan lainnya yaitu kesulitan dalam mengetahui permintaan barang akibatnya tidak ada rekapitulasi permintaan barang. Hasil dari penelitian tersebut adalah dengan adanya sistem informasi pengadaan barang proses pemesanan, penerimaan, pembayaran, retur barang, beserta laporannya menjadi lebih efisien dan juga dengan adanya sistem ini dapat membuat laporan rekapitulasi mengenai permintaan barang, sehingga perusahaan dapat mengetahui barang yang sering diminta. Penelitian kedua yang dilakukan oleh (Setyawan et al., 2019), dengan judul "Aplikasi Pengadaan Barang Berbasis Web Pada PT. Powerblock Indonesia". Masalah yang dihadapi pada perusahaan tersebut adalah banyaknya form yang harus dilampirkan dalam sekali pemesanan barang yang mengakibatkan pekerjaan mejadi lambat. Lambatnya pencarian dan pengarsipan data barang dan material karena disimpan dalam bentuk lembaran laporan pada rak arsip, sering terjadinya ketidaksesuaian data barang yang masuk pada bagian incoming dan barang yang dipesan pada bagian purchase order karena kurangnya informasi terkait barang dan pemesanan pada bagian incoming. Hasil dari penelitian tersebut yaitu untuk membantu PT. Powerblock Indonesia sebagai saran aplikasi untuk mempermudah dalama hal pekerjaan. Terdapat persamaan dan perbedaan antara penelitian ini dengan dua penelitian sebelumnya. Persamaan penelitian ini dengan penelitian sebelumnya yaitu menghasilkan data pemesanan dan laporan serta aplikasi yang berbasis website. Perbedaannya yaitu pada penelitian yang diusulkan, peneliti menggabungkan beberapa fitur dari penelitian sebelumnya sehingga menjadi lebih berkembang dengan adanya menu pemesanan, penerimaan serta pembayaran, penjualan dan juga terdapat fitur validasi ke setiap manajemen yang terlibat pada pengadaan ini dalam menu pemesanannya.

\section{METODE}

\section{A. Metode Waterfall}

Metode yang di gunakan dalam merancang dan membangun sistem informasi perhitungan harga pokok penjualan ini adalah metode waterfall pada Gambar 1. Tahap penelitian pada perancangan ini dilakukan dengan cara sebagai berikut (Sukamto \& Shalahuddin, 2014):

\section{a. Mengidentifikasi Masalah}

Tahap ini dilakukan dengan cara pengumpulan data baik dengan metode pengumpulan data primer maupun pengumpulan data sekunder untuk mengetahui proses bisnis yang terjadi dalam perusahaan. 
b. Tahap Analisis

Tahap analisis dilakukan secara intensif untuk menspesifikasikan kebutuhan sistem agar dapat dipahami sistem seperti apa yang dibutuhkan oleh pengguna.

c. Desain

Tahap desain adalah proses multi langkah yang fokus pada desain pembuatan program sistem termasuk struktur data, arsitektur sistem, representasi antarmuka, dan prosedur pengodean. Tahap ini mentranslasi kebutuhan sistem dari tahap analisis kebutuhan ke representasi desain agar dapat diimplementasikan menjadi program pada tahap selanjutnya.

d. Pengodean

Pada tahap pengodean, desain harus ditranslasikan ke dalam program sistem. Hasil dari tahap ini adalah program komputer sesuai dengan desain yang telah dibuat pada tahap desain.

e. Pengujian

Tahap pengujian fokus pada sistem dari segi logika dan fungsional dan memastikan bahwa semua bagian sudah diuji. Hal ini dilakukan untuk meminimalisir kesalahan (error) dan memastikan keluaran yang dihasilkan sesuai dengan yang diinginkan.

f. Pemeliharaan

Tidak menutup kemungkinan sebuah sistem mengalami perubahan ketika sudah dikirimkan ke pengguna. Perubahan bisa terjadi karena adanya kesalahan yang muncul dan tidak terdeteksi saat pengujian atau sistem harus beradaptasi dengan lingkungan baru. Tahap pemeliharaan dapat mengulangi proses pengembangan mulai dari analisis spesifikasi untuk perubahan sistem yang sudah ada, tapi tidak untuk sistem baru.

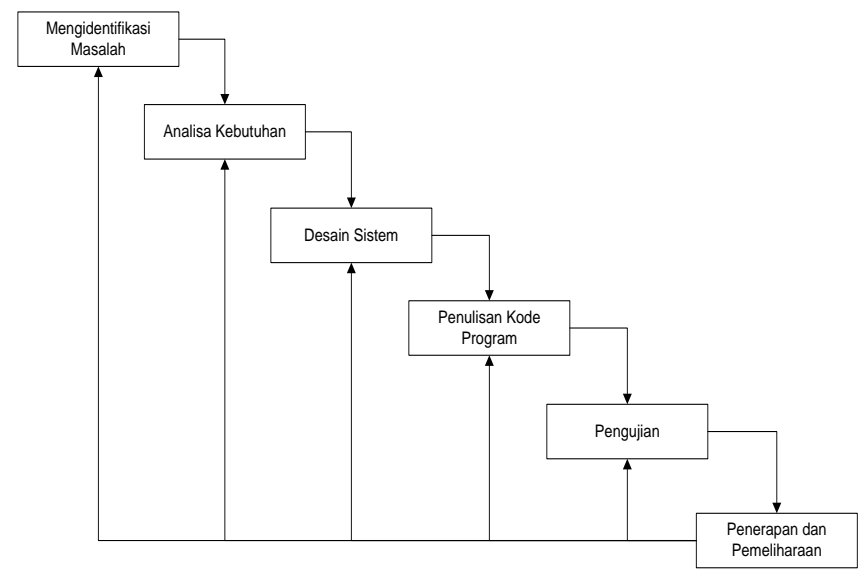

Gambar 1. Pemodelan Waterfall

\section{B. User Acceptance Test (UAT)}

User Acceptance Test (UAT) merupakan pengujian yang dilakukan oleh end-user, pihak yang langsung berinteraksi dengan sistem dan dilakukan verifikasi apakah fungsi yang ada telah berjalan sesuai dengan kebutuhan. Pengujian UAT dilakukan dengan menggunakan in-depth interview, yang hal tersebut dilakukan wawancara terhadap responden.

Wawancara yang efektif dapat dilakukan dengan instrumen yang terencana, seperti menggunakan struktur dan agenda yang mudah dipahami. Beberapa tahapan in-depth interview adalah menginterpretasikan hasil wawancara, mengkodekan dan mengkategorikan atau mengelompokkan datadata. Interpretasi secara umum menafsirkan maksud dari setiap jawaban untuk setiap pertanyaan atau pernyataan (Fitriana et al., 2018).

\section{HASIL DAN PEMBAHASAN}

\section{A. Analisis Kebutuhan Sistem}

Pada tahap ini dilakukan analisis kebutuhan sebagai penentu dari kebutuhan-kebutuhan yang diperlukan untuk proses perancangan aplikasi. Berikut pada Tabel 1. Merupakan kebutuhan-kebutuhan dari sistem. 
Tabel 1. Kebutuhan Sistem

\begin{tabular}{ll}
\hline No & Kebutuhan \\
\hline 1 & $\begin{array}{l}\text { Sistem dapat menampilkan data user, barang, supplier, akun, pembelian, penerimaan, } \\
\text { penjualan, pembayaran dan jurnal. }\end{array}$ \\
2 & $\begin{array}{l}\text { Sistem dapat menyediakan menu tambah, ubah dan batal untuk mengelola data user, } \\
\text { barang, supplier, akun, pembelian, penerimaan, penjualan, pembayaran dan jurnal. }\end{array}$ \\
3 & $\begin{array}{l}\text { Sistem dapat menampilkan data laporan pembelian, laporan penjualan, laporan } \\
\text { penerimaan, laporan perbandingan, laporan pembayaran, laporan jurnal, buku besar, }\end{array}$ \\
& $\begin{array}{l}\text { laba/rugi dan neraca saldo. } \\
\text { Sistem dapat melakukan aksi cetak dan export laporan. }\end{array}$ \\
\hline
\end{tabular}

\section{B. Gambaran Umum Sistem}

Gambaran umum sistem dari penelitian ini yaitu, admin dapat mengelola data user, data supplier, data barang, data akun, data purchase order, data penerimaan, data pembayaran, data penjualan dan data jurnal. Purchasing dapat mengelola data purchase order kemudian warehouse dapat mengelola data penerimaan barang , accounting dapat mengelola data pembayaran, penjualan dan data jurnal, cost control datapat mengelola data validasi purchase order dan general manager dapat mengelola data validasi purchase order dan dapat mengetahui informasi laporan pembelian, laporan penerimaan, laporan perbandingan, laporan penjualan, laporan pembayaran, laporan jurnal, laporan buku besar, laporan laba rugi dan laporan neraca. Gambaran umu system dapat dilihat pada Gambar 2.

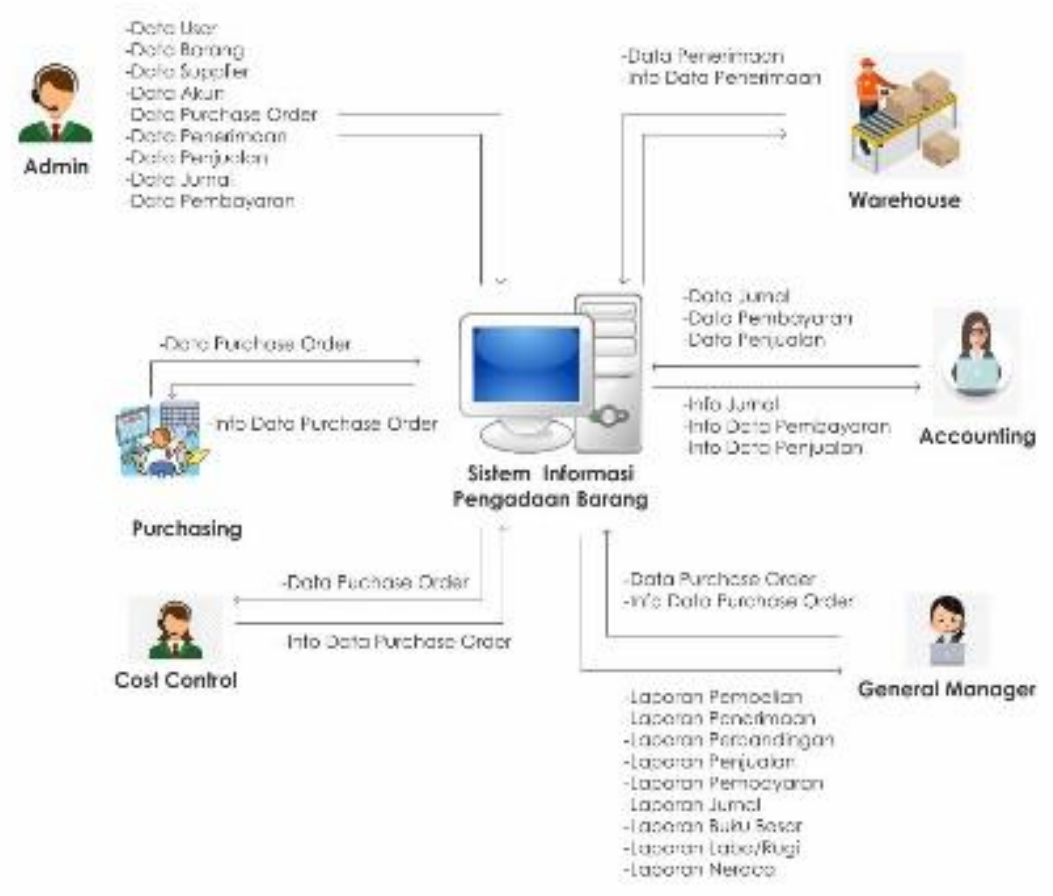

Gambar 2. Gambaran Umum Sistem

\section{Perancangan Sistem}

a. Data Flow Diagram Level 0

DFD level 0 merupakan diagram alir data yang menjelaskan tentang seluruh proses pengelolaan sistem dari pengguna DFD Level 0 yang terdiri terdiri dari 7 proses yakni mengelola mengelola data master, mengelola data purchase order, mengelola data penerimaan, mengelola data penjualan, mengelola data jurnal, mengelola data pembayaran, dan mengelola laporan. DFD Level 0 dapat dilihat pada Gambar 3. 


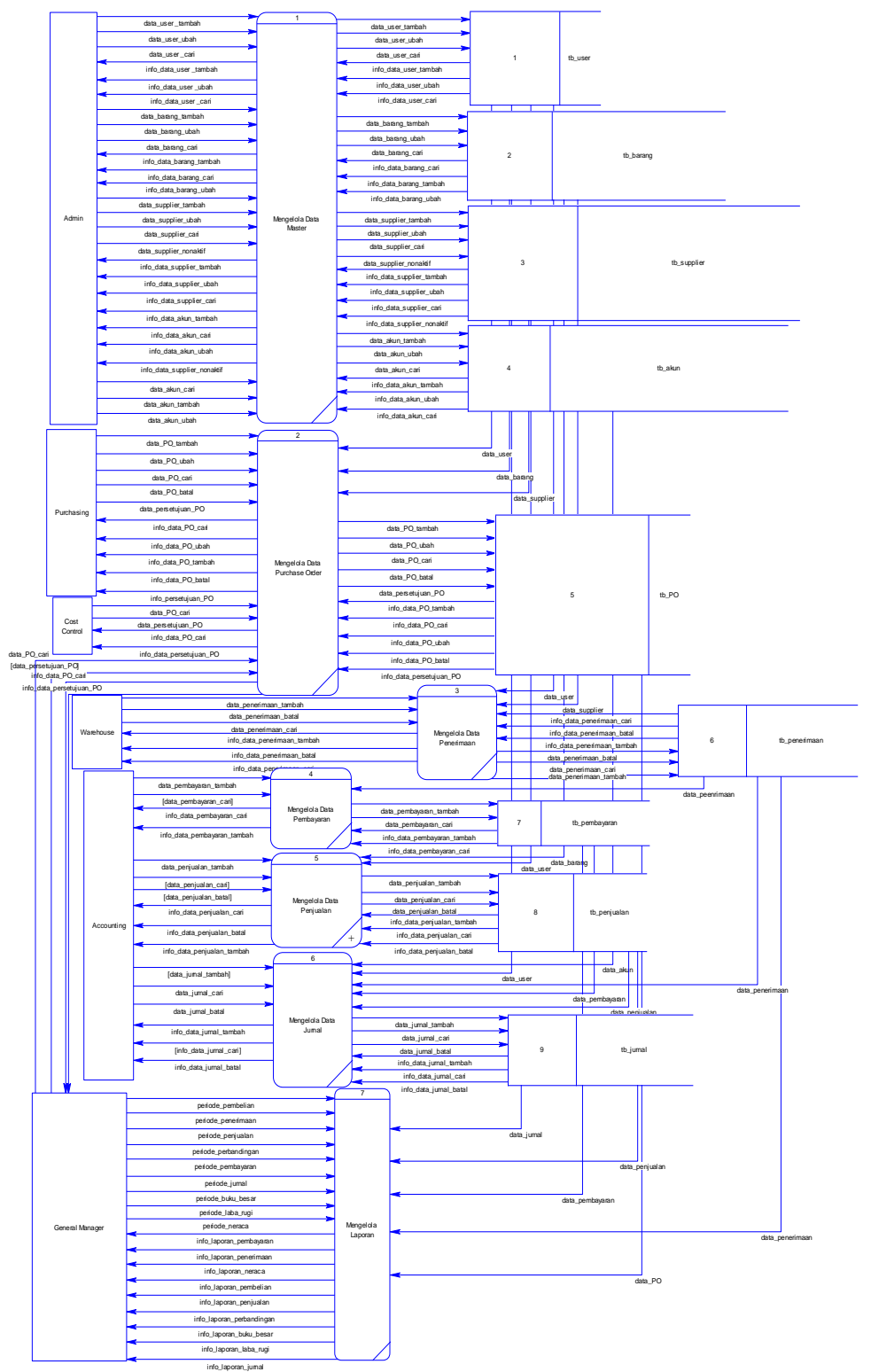

Gambar 3. Data Flow Diagram Level 0 Pengadaan Barang

\section{b. Data Flow Diagram Level 1}

DFD level 1 mengelola data purchase order menjelaskan tugas dari entitas purchasing, cost control, dan general manager yang memiliki 4 data store yaitu data user, data barang, data purchase order, dan data supplier. Terdapat 5 subprocess purchasing yaitu tambah data purchase order, ubah data purchase order, cari data purchase order, batal data purchase order dan mengelola persetujuan purchase order. Sedangkan entitas cost control dan general manager dapat mengelola data persetujuan purchase order dan mencari data purchase order. DFD level 1 mengelola data purchase order dapat diliat pada Gambar 4. 


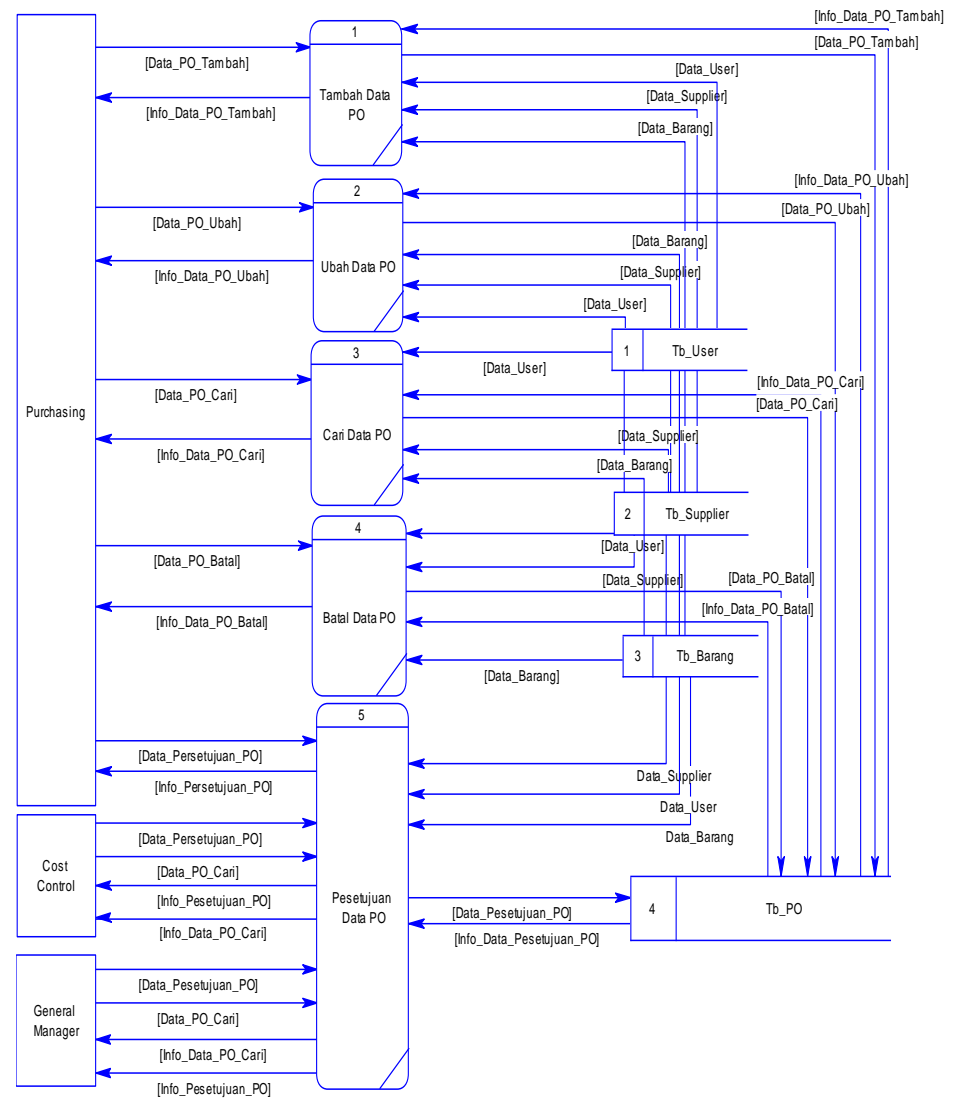

Gambar 4. Data Flow Diagram Level 1 Pengadaan Barang

\section{c. Physical Data Model}

Merupakan model yang menggunakan sejumlah tabel untuk menggambarkan data serta hubungan antara data-data tersebut. Setiap tabel mempunyai sejumlah kolom dimana setiap kolom memiliki nama yang unik(Rahmat Tullah, 2014; Ramadhani, 2011). Basis data merupakan salah satu bagian dalam rekayasa perangkat lunak yang terkomputerisasi dan bertujuan utama memelihara data yang sudah diolah atau media penyimpanan informasi agar dapat diakses dengan mudah dan cepat(A. S. \& Shalahuddin, 2013). Seperti yang ditunjukan pada Gambar 5.

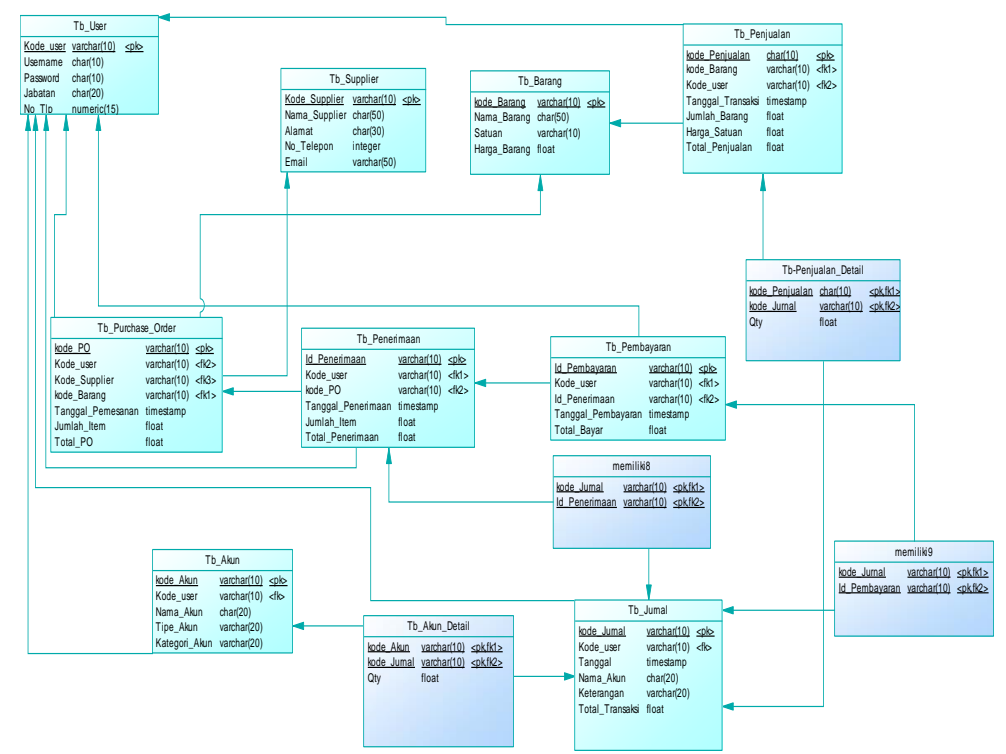

Gambar 5. PDM Pengadaan Barang 


\section{Tampilan Sistem}

\section{a. Halaman Purchase Order}

Halaman ini akan muncul ketika menekan tambah data, maka muncul form halaman tambah data purchase order. Setelah semua data tersebut diisi maka pilih simpan untuk menyimpan data tersebut. Dengan demikian data tersebut akan otomatis terkirim ke pihak cost control untuk meminta validasi data. Halaman tambah data purchase order dapat dilihat pada Gambar 6.

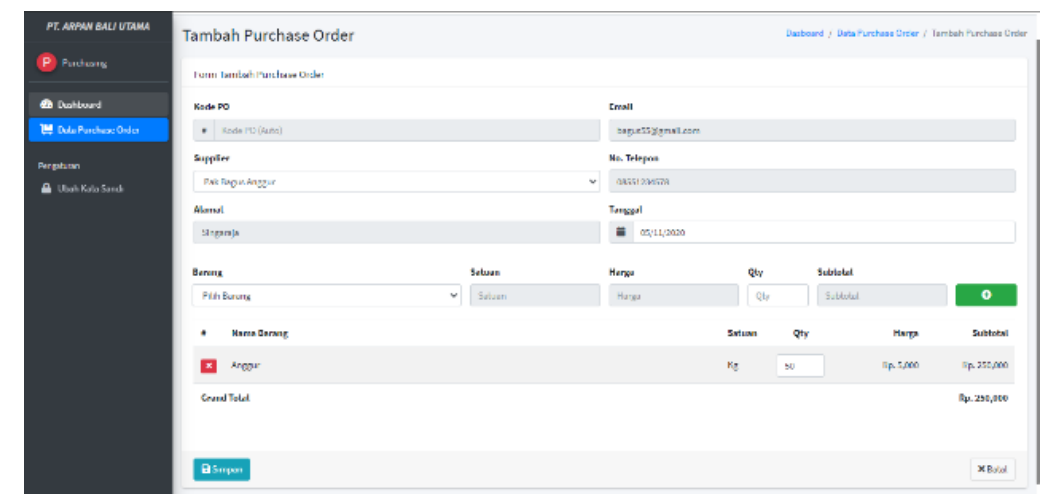

Gambar 6. Halaman Purchase Order

\section{b. Halaman Validasi Purchase Order}

Halaman validasi Purchase Order muncul ketika menekan data Purchase Order lalu tekan icon centang pada aksi ditabel purchase order, ketika data Purchase Order tersebut ingin divalidasi maka selanjutnya data tersebut akan otomatis masuk ke halaman general manager dengan tampilan yang sama. Selanjutnya ketika data tersebut sudah tervalidasi semua, maka akan masuk kembali ke menu purchasing. Halaman validasi purchase order pada dapat dilihat pada Gambar 7.

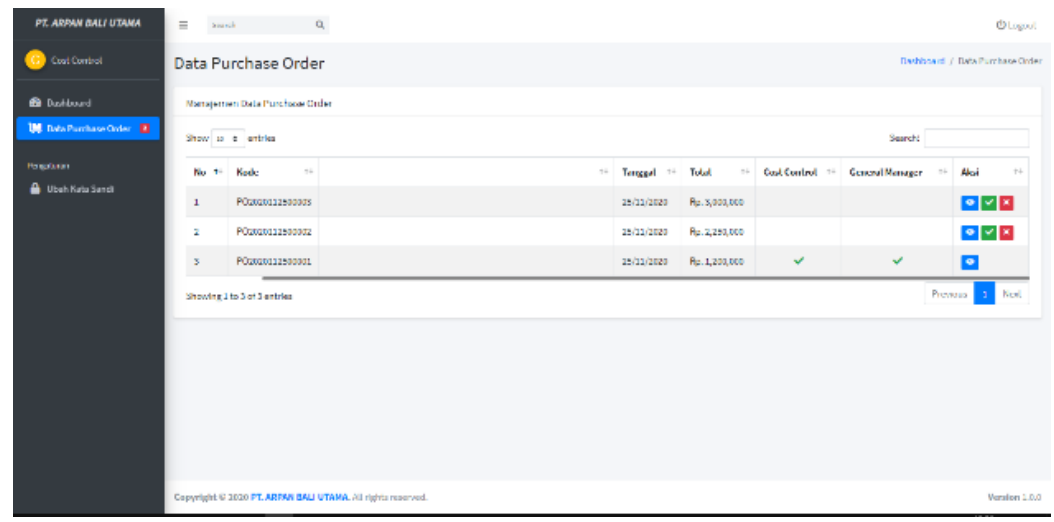

Gambar 7. Halaman Validasi Purchase Order

\section{c. Halaman Jurnal}

Halaman data jurnal muncul ketika user menekan aksi tambah data, maka akan muncul tampilan form data jurnal, jika form sudah terisi dengan benar maka tekan simpan untuk menyimpan data tersebut. Halaman data jurnal dapat dilihat pada Gambar 8. 


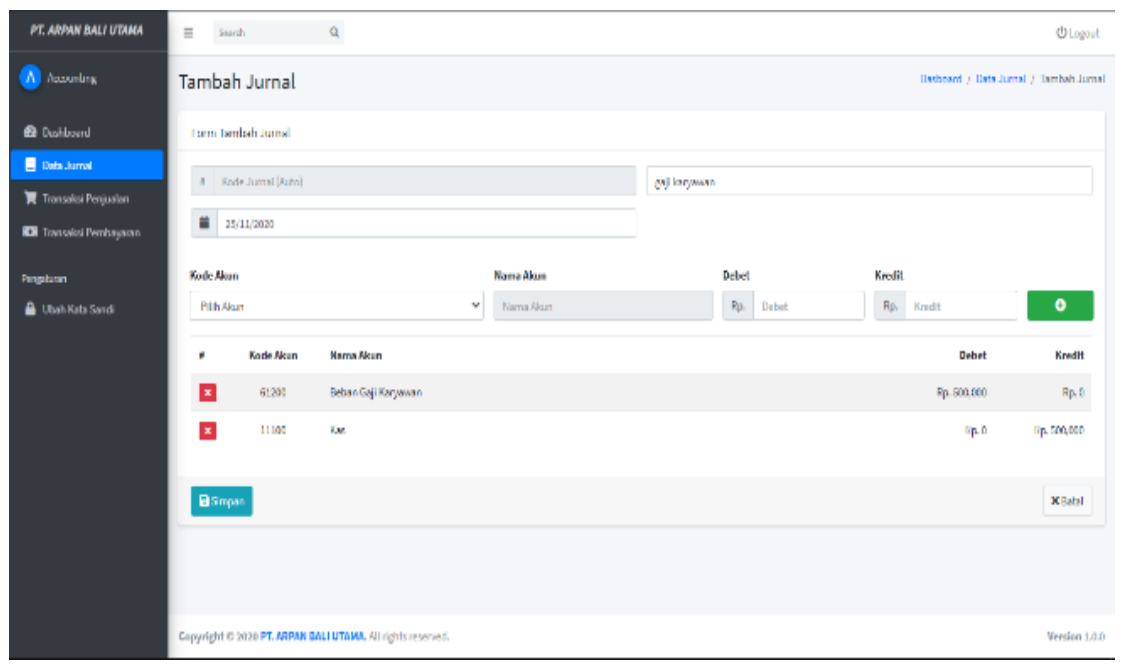

Gambar 8. Halaman Jurnal

\section{d. Halaman Laporan Pembelian}

Pada laporan pembelian, general manager dapat melihat transaksi-transaksi pembelian yang telah dilakukan serta dapat mencetak laporan tersebut selama masa periode yang dipilih. Laporan pembelian dapat dilihat pada Gambar 9.

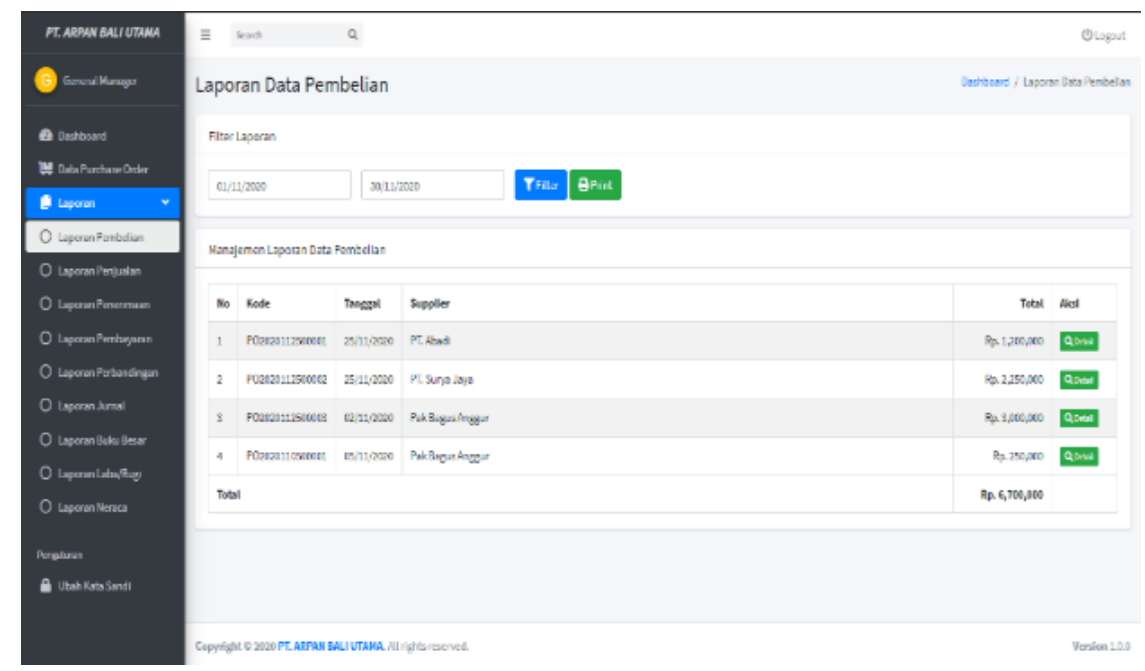

Gambar 9. Halaman Laporan Pembelian

\section{e. Halaman Laporan Perbandingan}

Pada laporan perbandingan, general manager dapat melihat perbandingan antara transaksi pembelian dengan penerimaan, dimana dari laporan ini general manager dapat mengetahui seberapa performa dari pihak supplier dalam menyelesaikan pesanannya serta dapat mencetak laporan tersebut selama masa periode yang dipilih. Laporan perbandingan dapat dilihat pada Gambar 10. 


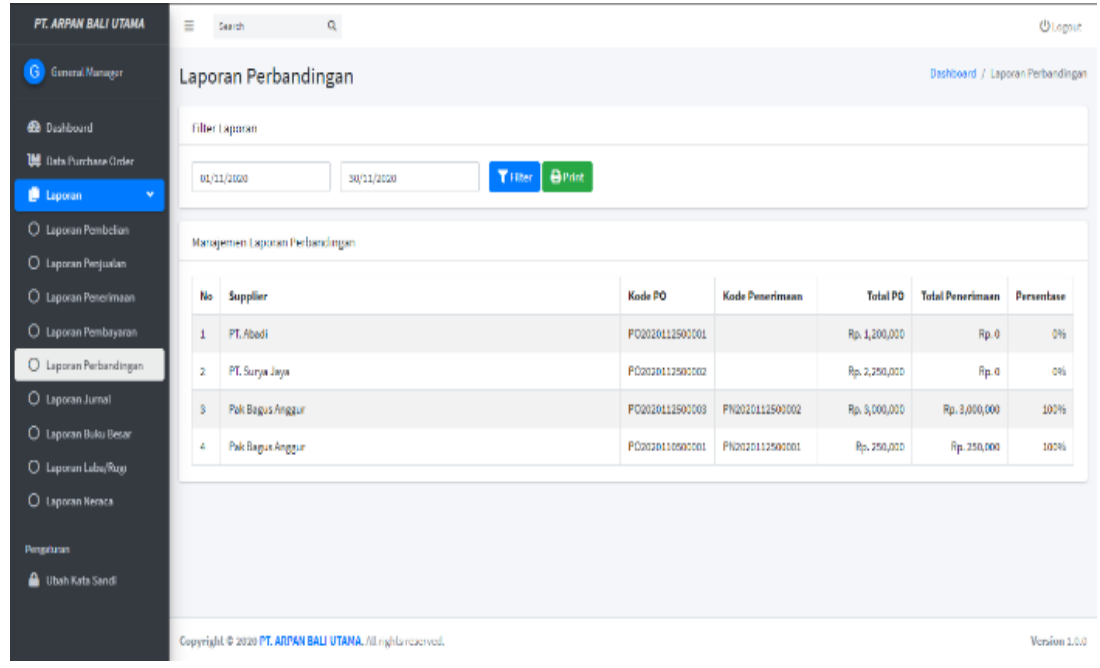

Gambar 10. Halaman Laporan Perbandingan

\section{f. Halaman Laporan Buku Besar}

Pada laporan buku besar, general manager dapat melihat gambaran keuangan perusahaan sesuai dengan akun-akun yang digunakan. Laporan buku besar dapat dilihat pada Gambar 11.

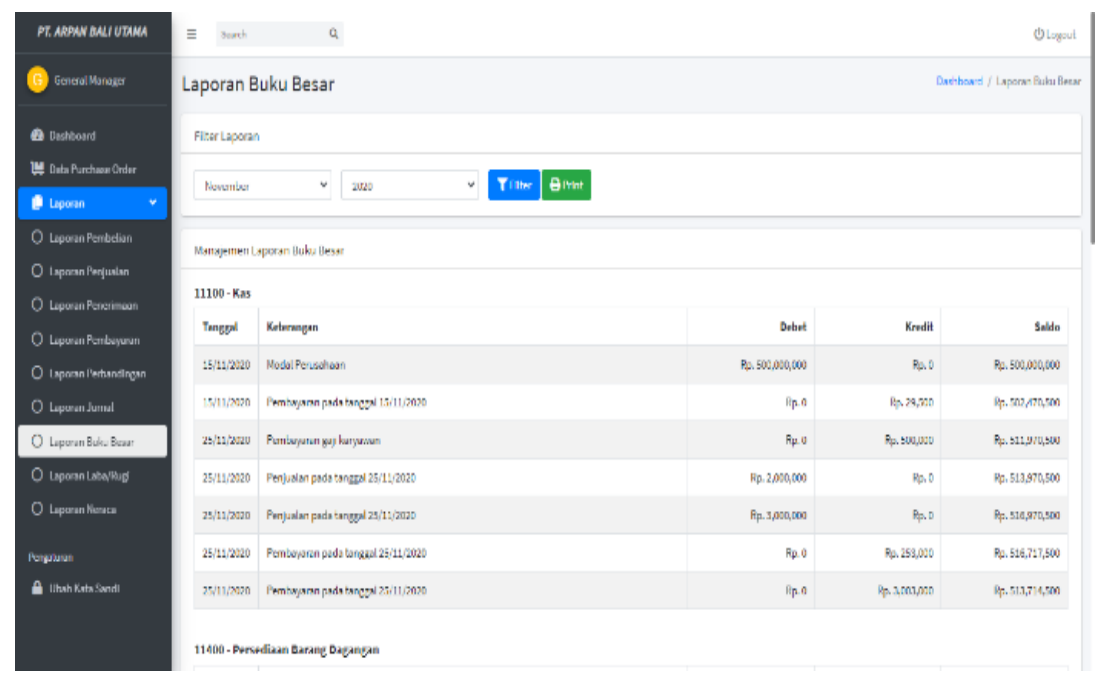

Gambar 11. Halaman Laporan Buku Besar

\section{E. Pengujian Sistem}

\section{a. Pengujian Black Box Sistem}

Proses pengujian menggunakan jenis pengujian black box testing, pengujian ini dimaksudkan untuk mengetahui kinerja dari aplikasi yang akan dibuat ini berjalan dengan baik atau tidak sesuai dengan harapan. Hasil pengujian black box dapat dilihat pada Tabel 2.

Tabel 2. Pengujian Black Box Sistem

\begin{tabular}{llll}
\hline Fungsi & Skenario & Hasil & Keterangan \\
\hline & $\begin{array}{l}\text { Login dengan Email dan } \\
\text { Password yang valid pada menu } \\
\text { halaman login }\end{array}$ & $\begin{array}{l}\text { User berhasil login sesuai } \\
\text { dengan hak akses. }\end{array}$ & Sesuai \\
Login & & & \\
& & & \\
& &
\end{tabular}




\begin{tabular}{|c|c|c|c|}
\hline Fungsi & Skenario & Hasil & Keterangan \\
\hline & $\begin{array}{l}\text { Login dengan salah satu field } \\
\text { yang tidak terisi atau email dan } \\
\text { password invalid }\end{array}$ & $\begin{array}{l}\text { Muncul pemberitahuan } \\
\text { username atau password salah } \\
\text { dan diperintahkan untuk } \\
\text { mengecek kembali }\end{array}$ & Sesuai \\
\hline \multirow{2}{*}{$\begin{array}{l}\text { Halaman } \\
\text { Pembelian }\end{array}$} & $\begin{array}{l}\text { Menambah data Purchase Order } \\
\text { dengan melengkapi seluruh } \\
\text { field yang ada pada form }\end{array}$ & $\begin{array}{l}\text { Sistem akan menampilkan } \\
\text { pesan "Transaksi berhasil } \\
\text { disimpan" }\end{array}$ & Sesuai \\
\hline & $\begin{array}{l}\text { Menambah data Purchase Order } \\
\text { dan mengosongkan salah satu } \\
\text { field pada form. }\end{array}$ & $\begin{array}{l}\text { Sistem akan menampilkan } \\
\text { pesan "filed tidak boleh } \\
\text { kosong". }\end{array}$ & Sesuai \\
\hline \multirow[t]{2}{*}{$\begin{array}{l}\text { Halaman } \\
\text { Laporan }\end{array}$} & $\begin{array}{l}\text { Memilih laporan dan } \\
\text { memasukan periode laporan } \\
\text { berdasarkan tanggal dan tahun }\end{array}$ & $\begin{array}{l}\text { Memunculkan hasil pencarian } \\
\text { sesuai yang diinginkan }\end{array}$ & Sesuai \\
\hline & Mencetak laporan & Berhasil mencetak laporan & Sesuai \\
\hline
\end{tabular}

\section{b. Pengujian User Acceptance Test (UAT)}

Hasil pengujian Sistem Informasi Pengadaan Barang Berbasis Web Pada PT. Arpan Bali Utama menggunakan metode pengujian User Acceptance Test (UAT). Pengujian ini melibatkan 1 General Manager, 2 Accounting, 1 Purchasing, 1 Cost Control dan 11 bagian staff gudang dengan jumlah 16 responden.

Tabel 3. Hasil Kuisioner

\begin{tabular}{|c|c|c|c|c|c|c|}
\hline No. & Kuisioner & SS & $\mathrm{S}$ & KS & TS & STS \\
\hline 1. & $\begin{array}{l}\text { Sistem } \\
\text { Informasi } \\
\text { Pengadaan } \\
\text { Barang yang } \\
\text { dibangun } \\
\text { sesuai } \\
\text { kebutuhan. }\end{array}$ & 6 & 10 & & & \\
\hline 2. & $\begin{array}{l}\text { Tampilan } \\
\text { Sistem } \\
\text { Informasi } \\
\text { Pengadaan } \\
\text { Barang yang } \\
\text { dibangun } \\
\text { mudah } \\
\text { dipahami. }\end{array}$ & 5 & 9 & 2 & & \\
\hline 3. & $\begin{array}{l}\text { Proses } \\
\text { pemesanan } \\
\text { barang dapat } \\
\text { dengan } \\
\text { mudah } \\
\text { dilakukan. }\end{array}$ & 7 & 9 & & & \\
\hline 4. & $\begin{array}{l}\text { Hasil yang } \\
\text { diperoleh } \\
\text { sesuai dengan } \\
\text { kebutuhan. }\end{array}$ & 7 & 9 & & & \\
\hline 5. & $\begin{array}{l}\text { Laporan yang } \\
\text { dihasilkan } \\
\text { lebih cepat } \\
\text { dan akurat. }\end{array}$ & 5 & 9 & 2 & & \\
\hline TOTAL & & 30 & 46 & 4 & & \\
\hline
\end{tabular}


Tabel 4. Pengujian User Acceptance Test (UAT)

\begin{tabular}{ll}
\hline & $\begin{array}{l}\text { jumlah kuisioner* jumlah responden } * \text { nilai } \\
\text { tertinggi kuisioner }\end{array}$ \\
\cline { 2 - 2 } Skor tertinggi UAT (f) & $5 * 16 * 5=400$ \\
\hline Sangat Setuju (SS) & $30 * 5=150$ \\
Setuju (S) & $46 * 4=184$ \\
Kurang Setuju (KS) & $4 * 3=12$ \\
Tidak Setuju (TS) & $0 * 2=0$ \\
Sangat Tidak Setuju (STS) & $0 * 1=0$ \\
Total & $150+184+12+0+0=346$ \\
Presentase (Total / $\mathrm{f} * 100 \%)$ & $346 / 400 * 100 \%=\mathbf{8 6 . 5 \%}$ \\
\hline
\end{tabular}

Tabel 5. Persentase Nilai User Acceptance Test (UAT)

\begin{tabular}{ll}
\hline Persentase & Keterangan \\
\hline $0 \%-19.99 \%$ & Sangat Tidak Setuju \\
$20 \%-39.99 \%$ & Tidak Setuju \\
$40 \%-59.99 \%$ & Kurang Setuju \\
$60 \%-79.99 \%$ & Setuju \\
$80 \%-100 \%$ & Sangat Setuju \\
\hline
\end{tabular}

Berdasarkan hasil pengujian User Acceptance Test (UAT) yang dilakukan pada PT. Arpan Bali Utama, dapat dilihat dari tabel persentase nilai User Acceptance Test (UAT) bahwa program yang dibangun memiliki penilaian sangat setuju dengan presentase $86.5 \%$ yang berarti Sistem Sistem Informasi Pengadaan Barang Berbasis Web Pada PT. Arpan Bali Utama sudah sesuai dengan kebutuhan dari perusahaan tersebut.

\section{SIMPULAN DAN SARAN}

Berdasarkan penelitian yang dilakukan dengan merancang, membangun, menguji, dan menganalisis, dapat disimpulkan sebagai berikut:

(1) Proses perancangan Sistem Informasi Pengadaan Barang Pada PT. Arpan Bali Utama ini dimulai dari pengumpulan data yang dibutuhkan dalam pembuatan sistem, kemudian dianalisa kebutuhan sistemnya, selanjutnya merancang alur sistem yang akan dibangun, digambarkan dengan system flow diagram, data flow diagram, conceptual data model, physical data model, dilanjutkan dengan merancang user interface. Proses pembangunan sistem menggunankan bahasa pemrograman PHP dan database MySQL.

(2) Sistem Informasi Pengadaan Barang ini mampu melakukan beberapa proses yang diharapkan, yaitu mengelola mengelola data user, data akun, data supplier, data barang, data pemesanan, data penerimaan, data pembayaran, data penjualan, data jurnal dan laporan yang dihasilkan yaitu laporan pembelian, laporan penjualan, laporan penerimaan, laporan pembayaran, laporan perbandingan, laporan jurnal, laporan buku besar, laporan laba/rugi dan laporan neraca.

(3) Dari hasil pengujian menggunakan metode black box testing dan pengujian User Acceptance Test (UAT). Metode black box testing menunjukkan bahwa semua fitur yang terdapat dalam sistem berjalan dengan baik sesuai fungsinya. Sedangkan hasil pengujian User Acceptance Test terhadapat sistem pendukung keputusan ini memperoleh persentase $86.5 \%$. 


\section{Ucapan Terima Kasih}

Tidak lupa dalam penelitian ini saya ucapkan terimakasih kepada semua pihak yang terlibat terutama PT. Arpan Bali Utama yang telah meluangkan waktunya untuk memberikan informasi sehingga penelitian ini dapat berjalan dengan baik.

\section{Daftar Pustaka}

A. S., R., \& Shalahuddin, M. (2013). Rekayasa Perangkat Lunak Terstruktur Dan Berorientasi Objek. Informatika.

Fitriana, J., Ripanti, E. F., \& Tursina. (2018). Sistem Pendukung Keputusan Pemilihan Mahasiswa Berprestasi dengan Metode Profile Matching ( Studi Kasus : Fakultas Teknik UNTAN ). 6(4), 157-164.

Nur Majdina Hibatur Rahman, \& Sri Muryani. (2017). Aplikasi Akuntansi Untuk Menyusun Laporan Keuangan Pada Koperasi Amanah Jakarta. INFORMATION MANAGEMENT FOR EDUCATORS AND PROFESSIONALS, Vol.1, No., 155-168.

Oktarina, F., \& Widjaja, A. (2019). RANCANG BANGUN SISTEM INFORMASI PENGADAAN BARANG PADA CV. MITRA ANUGERAH. IDEALIS, 2.

Rahmat Tullah. (2014). Evaluasi Penerapan Sistem Informasi Pada Politeknik Lp3i Jakarta Dengan Metode Pieces. Jurnal Sisfotek Global, Vol 4 No 1.

Ramadhani. (2011). Pembangunan Sistem Informasi Penerimaan Siswa Baru Di Sekolah Menengah Kejuruan Al-Irsyad Tegal. Sentra Penelitian Engineering Dan Edukasi, 131-139.

Setyawan, A., Muttaqin, Z., \& Angpa, S. S. (2019). Aplikasi Pengadaan Barang Berbasis Web Pada PT. Powerblock Indonesia. Prosisko, 6.

Sukamto, \& Shalahuddin, M. (2014). Rekayasa Perangkat Lunak. Informatika.

Yanto, R. (2016). Manajemen Basis Data Menggunakan MySQL. Deepublish. 